\title{
Lost in translation: What do Engel curves tell us about the cost of living?
}

Ingvild Almås, Timothy K.M. Beatty and Thomas F. Crossley

ESCoE Discussion Paper 2019-09

May 2019 
Lost in translation: What do Engel curves tell us about the cost of living? Ingvild Almås, Timothy K.M. Beatty and Thomas F. Crossley

ESCoE Discussion Paper No. 2019-09

May 2019

\begin{abstract}
The Hamilton method for estimating CPI bias is simple, intuitive, and has been widely adopted. We show that the method conflates CPI bias with variation in cost of-living growth across income levels. Assuming a single price index across the income distribution is not consistent with the downward sloping Engel curves that are necessary to implement the method. We suggest an approach that disentangles genuine CPI bias from differences caused by comparing changes in the cost of living across income levels- non-homotheticity. For the period Hamilton studies, this yields substantially lower estimates of CPI bias and therefore implies lower income growth.
\end{abstract}

Keywords: Inflation, CPI-bias, Hamilton Method, Engel Curves

JEL classification: D11, D12, E31

Ingvild Almås, IIES Stockholm University and Norwegian School of Economics, ingvild.almas@iies.su.se, Timothy K.M. Beatty, University of California, Davis, tbeatty@ucdavis.edu and Thomas F. Crossley, University of Essex and Institute for Fiscal Studies, tcross@essex.ac.uk

Published by:

Economic Statistics Centre of Excellence

National Institute of Economic and Social Research

2 Dean Trench St

London SW1P 3HE

United Kingdom

www.escoe.ac.uk

ESCoE Discussion Papers describe research in progress by the author(s) and are published to elicit comments and to further debate. Any views expressed are solely those of the author(s) and so cannot be taken to represent those of the Economic Statistics Centre of Excellence (ESCoE), its partner institutions or the Office for National Statistics (ONS).

(C) Ingvild Almås, Timothy K.M. Beatty and Thomas F. Crossley 


\title{
Lost in translation: What do Engel curves tell us about the cost of living? *
}

\author{
Ingvild Almås \\ IIES Stockholm University \\ Norwegian School of Economics \\ Thomas F. Crossley \\ University of Essex \\ Institute for Fiscal Studies
}

\author{
Timothy K.M. Beatty \\ University of California, Davis
}

May 2019

\begin{abstract}
The Hamilton method for estimating CPI bias is simple, intuitive, and has been widely adopted. We show that the method conflates CPI bias with variation in costof-living growth across income levels. Assuming a single price index across the income distribution is not consistent with the downward sloping Engel curves that are necessary to implement the method. We suggest an approach that disentangles genuine CPI bias from differences caused by comparing changes in the cost of living across income levels - non-homotheticity. For the period Hamilton studies, this yields substantially lower estimates of CPI bias and therefore implies lower income growth.
\end{abstract}

\footnotetext{
*Almås acknowledges valuable support from Vetenskapsrådet (the Swedish Research Council), ESOP, University of Oslo, The Choice Lab, Norwegian School of Economics, and the "young research talents" program of the Norwegian Research Council. Crossley gratefully acknowledges support for this research from the Economic and Social Research Council (ESRC) through the Research Centre on Micro-Social Change (MiSoC) at the University of Essex (grant number ES/L009153/1) and Centre for Microeconomic Analysis of Public Policy at the Institute for Fiscal Studies (grant number ES/M010147/1.) We would like to thank Orazio Attansio, Garry Barrett, Richard Blundell, Timo Boppart, Chris Carroll, Angus Deaton, Erwin Diewert, Bruce Hamilton, Jeff LaFrance, Valerie Lechene, Emi Nakamura, Ian Preston, David Strömberg, Guglielmo Weber, and participants in a number of seminars for helpful comments, and Peter Levell for assistance with the CE data. All remaining errors are our own.
} 


\section{Introduction}

Measuring economic progress over time and assessing cross-country differences in living standards are central concerns of researchers, policy makers, and international institutions. Such comparisons require accurate measures of the cost of living with which to deflate nominal measures of economic activity or economic resources. Price indices and PPP calculations, such as the Consumer Price Index (CPI) and the purchasing power parities implicit in the Penn World Tables, are commonly used to this end. However, there are longstanding concerns regarding the many biases associated with traditional approaches to price index construction. These include outlet bias, substitution bias, and biases associated with failing to deal fully with quality changes and the introduction of new goods. See Diewert (1987, 1993, 1995); Bils and Klenow (2001a,b); Greenlees and McClelland (2011); Reinsdorf (1998, 1993); Boskin and Jorgenson (1997); Boskin et al. (1998); Triplett (2001); Hausman (2003); Lebow and Rudd (2003); Schultze (2003); Nordhaus (1998); Pollak (1998); Hausman and Leibtag (2009) for biases in the CPI, Broda and Weinstein (2010) for discussion of measurement issues in the underlying BLS price series, and Neary (2004); Hill (2004); Deaton and Heston (010a); Almås (2012) for corresponding concerns with PPP calculations.

In this paper we reconsider a popular approach to this problem: the "Hamilton Method" proposed by Bruce Hamilton (Hamilton, 1998, 001a). Stagnant deflated incomes in the United States during the 1970s and 80s concerned economists and policy makers. Nakamura (1995) noted that aggregate food budget shares declined throughout the period. That the food budget share falls with income - Engel's "law" (Engel, 1857, 1895) - is among the best known empirical regularities in economics. This suggested that incomes were growing, but standard methods failed to capture this growth. An appealing explanation was that the CPI overestimated increases in the cost of living over time, so that deflated income growth had been underestimated. Hamilton formalized this intuition, proposing a way of using micro data to estimate the correction to the CPI required for food Engel curves to be stable over time. Among the attractions of this method are that it is simple and intuitively appealing, has modest data requirements and offers an omnibus approach to assessing the multitude 
of potential biases in previously available indices like the CPI, rather than a piecemeal approach of assessing one bias at a time. Consequently, the Hamilton method has been applied widely, see Hamilton (001a,b); Costa (2001); Beatty and Larsen (2005); Brzozowski (2006); Larsen (2007); Gibson et al. (2008); Xu and Zeng (2009); Barrett and Brzozowski (2010); Gibson and Scobie (2010); Chung et al. (2010); Clerc et al. (2011); Olivia and Gibson (2012); de Carvalho Filho and Chamon (2012); Nakamura et al. (2016); Sacerdote (2017). An analogous approach (referred to as the "Engel method") has also been applied to spatial comparisons across and within countries, see Almås (2012); Almås and Johnsen (2018); Chattopadhyay (2010); Coondoo et al. (2011). In a series of papers discussing the time path of poverty in the U.S., Bruce Meyer and James Sullivan refer to the Hamilton method as important evidence of upward bias in the CPI (Meyer and Sullivan, 2009, 2011, 2012) and the World Bank recently applied the Hamilton method in 16 African countries to assess CPI bias and reassess progress on poverty reduction (Dabalen et al., 2016).

We show that the Hamilton method is not internally consistent. We then propose a method by which it can be made consistent and apply this improvement to Hamilton's data. The problem with the original Hamilton method arises because, on the one hand, the method estimates a single price index and interprets that price index as the cost of living index for all households. This interpretation implies that the cost of living index for an individual household does not depend on the utility (and hence income) of the household. If relative prices are changing (the only interesting case) this can only be true if preferences are homothetic. On the other hand, the method requires that preferences are not homothetic. Homotheticity implies that budget shares are independent of real income, and so are also independent of any bias in, or corrections to, the deflator. In other words, if preferences are such that the method can be implemented, there is not a single cost of living index to identify, and if preferences are such that there is a single cost of living index to identify, the method will not work.

Because food shares fall with income, preferences cannot be homothetic. Richer and poorer households have different consumption baskets and experience different changes in the cost of living. The Hamilton method and the CPI each estimate changes in the cost of 
living at specific points in the income distribution. However, they need not, and in general will not, estimate changes in the cost of living at the same point in the income distribution. Put simply, the Hamilton method conflates CPI bias with variation in inflation across income levels.

We overcome this problem by determining whose cost of living is being measured by the Hamilton method and then developing a theoretically consistent adjustment, which yields the cost of living for any point in the income distribution. To this end, we apply a method due to Muellbauer (1976) (see also Deaton (1998)) to determine the point in the income distribution where changes in the cost of living are best approximated by the CPI. Our method then gives us the change in cost of living at this point, from which we can calculate CPI bias. This allows us to separate genuine CPI bias from the differences in experienced inflation at the different points in the income distribution. For the period Hamilton studies, our method reveals significant upward bias in the CPI, but the estimated bias is smaller than that obtained by Hamilton's method.

Our main contribution - showing how to account for nonhomothetic preferences when using Engel curve shifts to evaluate price indices or calculate real incomes - adds to a growing literature which emphasizes the importance of non-homothetic preferences in the analysis of growth, income, and development. More generally, because our paper focuses on the measurement of CPI, and the CPI is often used as a deflator in studies of growth in consumption and income, our results also have direct implications for studies that seek to measure economic progress across time and/or space. We now turn to a description of the Hamilton method and the internal inconsistency of the method (Section 2) and a discussion of how we can make the method internally consistent by decomposing the measured "bias" into "CPI bias" and an effect due to non-homotheticity (Section 3). After this we apply our suggested decomposition to the study of the CPI in the same period as Hamilton studies and show that there is a substantial bias in the CPI, but it is smaller than that suggested by Hamilton (Section 4). Section 5 concludes. 


\section{The Hamilton Method}

The reasoning underpinning the Hamilton method seems straightforward. If preferences are stable over time and the CPI accurately measures cost of living then we would expect households at the same level of CPI-deflated income to allocate the same share of their budgets to food. Controlling for other possible influences on spending patterns, the food budget share at a given level of deflated income should be constant through time. If households at the same levels of deflated-income appear to be spending different shares of their budget on food over time, and this cannot be explained by other factors, it implies that true deflated income is changing even when measured deflated income is not. The Hamilton method ascribes this to mismeasurement of changes in the cost of living.

Most applications of the Hamilton method assume Almost Ideal Demand preferences (Deaton and Muellbauer, 1980), which implies Engel curves of the Working-Leser form. The food Engel curve is given by:

$$
w_{h, r, t}^{f}=\alpha^{f}+\gamma^{f f} \ln \left(\frac{p_{r, t}^{f}}{p_{r, t}^{n}}\right)+\beta^{f} \ln \left(\frac{x_{h, t}}{P_{r, t}}\right),
$$

where $h$ indexes households ${ }^{1}, r$ indexes regions, $t$ indexes time, $x_{h, r, t}$ is nominal income (or total expenditure), $\frac{p_{r, t}^{f}}{p_{r, t}^{r}}$ is the price of food $(f)$ relative to nonfood $(n)$ and $P_{r, t}$ is a price index. $^{2}$ The functional form assumption here often comes at little cost. Clearly, to draw unique inferences about deflated income from a budget share requires a monotonic relationship between the two. Empirically, the food share usually provides this. Moreover, the food share often turns out to be well approximated by a linear function of the logarithm of deflated income (though shares of some other goods are not), particulaly in developed economies. See Banks et al. (1997a) as one example.

In practice, with U.S. data, levels of food and non-food prices are not observed but their inflation rates are. These inflation rates are assumed to be measured with error. Following

\footnotetext{
${ }^{1}$ We use household as the unit of observation throughout because micro level expenditure data typically come at the household level.

${ }^{2}$ This is a two-good demand system for food and nonfood as in Hamilton (001a) or Costa (2001). Costa (2001) also considers Recreation / Non Recreation but her main results focus on food/non-food. The two good system implies either within group homotheticity or fixed within group relative prices.
} 
Hamilton, we write

$$
p_{r, t}^{k}=p_{r, 0}^{k}\left(1+\Pi_{r, t}^{k}\right)\left(1+E_{r, t}^{k}\right),
$$

where $\Pi_{r, t}^{k}$ is the observed inflation rate in the price of good $k$ to period $t$ in region $r$ and $E_{r, t}^{k}$ captures the difference between the true and observed inflation rates. Similarly, the overall price index $P_{r, t}$ can be written as a function of the base period value of the price index, the observed CPI and a term $E_{r, t}$ that captures the difference between the growth of the CPI and the true growth in $P_{r, t}$ :

$$
P_{r, t}=P_{r, 0} C P I_{r, t}\left(1+E_{r, t}\right) .
$$

Then:

$$
\begin{aligned}
w_{h, r, t}^{f} & =\alpha^{f}+\gamma^{f f} \ln \left(\frac{p_{r, 0}^{f}\left(1+\Pi_{r, t}^{f}\right)\left(1+E_{r, t}^{f}\right)}{p_{r, 0}^{n}\left(1+\Pi_{r, t}^{n}\right)\left(1+E_{r, t}^{N}\right)}\right)+\beta^{f} \ln \left(\frac{x_{h, r, t}}{P_{r, 0} \mathrm{CPI}_{r, t}\left(1+E_{r, t}\right)}\right), \\
& =\alpha^{f}+\gamma^{f f} \ln \left(\frac{1+\Pi_{r, t}^{f}}{1+\Pi_{r, t}^{n}}\right)+\beta^{f} \ln \left(\frac{x_{h, r, t}}{\mathrm{CPI}_{r, t}}\right) \\
& +\gamma^{f f}\left[\ln \left(1+E_{r, t}^{f}\right)-\ln \left(1+E_{r, t}^{n}\right)\right]-\beta^{f} \ln \left(1+E_{r, t}\right)+\gamma^{f f} \ln \left(\frac{p_{r, 0}^{f}}{p_{r, 0}^{n}}\right)-\beta^{f} \ln P_{r, 0} .
\end{aligned}
$$

The last term $\left[\gamma^{f f} \ln \left(\frac{p_{r, 0}^{f}}{p_{r, 0}^{n}}\right)-\beta^{f} \ln P_{r, 0}\right]$ varies only by region and so can be captured by region dummies. Hamilton makes two further assumptions. First, he assumes that $E_{r, t}^{f}$, $E_{r, t}^{n}$ and $E_{r, t}$ vary with time only. Second, in Hamilton's reported estimates, and in all the literature that follows, it is assumed that the difference between the true and observed 
inflation rates are identical for food and non-food, i.e. $\ln \left(1+E_{t}^{f}\right)-\ln \left(1+E_{t}^{n}\right)=0 .{ }^{3}$ Thus:

$$
\begin{aligned}
w_{h, r, t}^{f} & =\alpha^{f}+\gamma^{f f} \ln \left(\frac{1+\Pi_{r, t}^{f}}{1+\Pi_{r, t}^{n}}\right)+\beta^{f} \ln \left(\frac{x_{h, r, t}}{\mathrm{CPI}_{r, t}}\right) \\
& +\gamma^{f f}\left[\ln \left(1+E_{t}^{f}\right)-\ln \left(1+E_{t}^{n}\right)\right]-\beta^{f} \ln \left(1+E_{t}\right)+\sum_{r} \delta^{r} D^{r} \\
& =\alpha^{f}+\gamma^{f f} \ln \left(\frac{1+\Pi_{r, t}^{f}}{1+\Pi_{r, t}^{n}}\right)+\beta^{f} \ln \left(\frac{x_{h, r, t}}{\mathrm{CPI}_{r, t}}\right)+\sum_{t} \delta^{t} D^{t}+\sum_{r} \delta^{r} D^{r},
\end{aligned}
$$

where $D^{r}$ are region dummies, $D^{t}$ are time dummies, $\delta^{r}$ and $\delta^{t}$ are coefficients, and in particular, $\delta^{t}=-\beta^{f} \ln \left(1+E_{t}\right)$. This equation can be taken to data.

Intuitively, $E_{t}$ is chosen to minimize the distance between the Engel curves in the base period and period $t$. Equivalently, the Hamilton method estimates the price index, $P_{r, t}=$ $P_{r, 0} \mathrm{CPI}_{r, t}\left(1+E_{t}\right)$ as the translation to nominal income that aligns the food Engel curves (after accounting for relative price effects and the effects of changing demographics). This is summarized in Figure 1a. Figure 1a shows the region/period $r, t$ Engel curve and the base period (0) Engel curve, for simplicity, both are drawn at base period relative prices $\left(\frac{p_{0}^{f}}{p_{0}^{n}}\right)$. The correction $E_{t}$ shifts the region/period $r, t$ Engel curve back onto the region/period 0 Engel curve, as indicated by the arrows. If, as expected, the CPI is upward biased, from Equation (3) we should have $\left(1+E_{t}\right)<1$ and so $E_{t}<0$. However, Hamilton reports $-E_{t}$ as cumulative bias, to give a positive number (and we shall follow this convention below.)

Hamilton incorrectly interprets $P_{r, t}$ as the true cost of living index. ${ }^{4} E_{t}$ is then interpreted as the bias in the CPI relative to growth in the cost of living. $P_{r, t}$ is a price index, but as we show in the next section, if relative prices vary it is the true cost of living index at, at most, one point in the income distribution. This means that $E_{t}$ can not, in general, be interpreted as the bias in the CPI relative to changes in the cost of living.

The problem is that the Hamilton method estimates a single price index and interprets that price index as the cost of living index for all households. This interpretation implies that the cost of living index for an individual household does not depend on the utility - and

\footnotetext{
${ }^{3}$ In his development of the method, Hamilton allows that $E_{t}^{f}$ and $E_{t}^{n}$ may differ. He suggests that his method will understate the bias in the overall CPI as observed food inflation likely understates true food inflation by less than observed non-food inflation understates true non-food inflation.

${ }^{4}$ Hamilton (001a), page 622, just above Equation 2.
} 
Figure 1: The Hamilton method

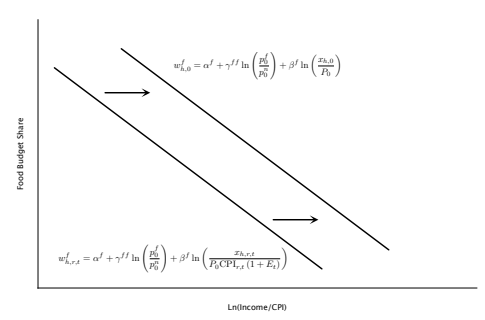

(a) Non-homothetic preferences

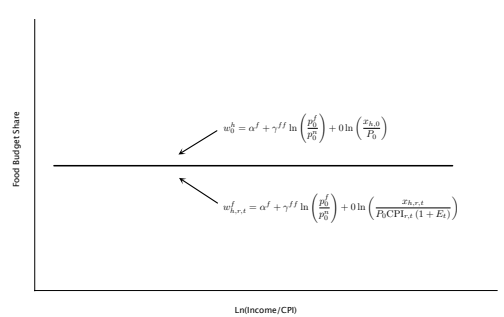

(b) Homothetic Preferences

Note: The figure illustrates a shift in an Engel curve induced by a correction of a bias to the CPI. Without the correction for the bias correction $E_{t}$ the Engel curve for period/region $r, t$ would lie left of the Engel curve for period/region 0. The correction $E_{t}$ shifts the Engel curve back onto the region/period 0 Engel curve.

hence income - of the household. This can only be generally true if preferences are homothetic. ${ }^{5}$ But if preferences are homothetic, the Hamilton method cannot be implemented. Homotheticity implies that budget shares are flat with regard to income, as illustrated in Figure $1 \mathrm{~b}$ with the 0 coefficient on the logarithm of deflated income. In this case, food shares contain no information about deflated income (or biases in deflated income). After adjusting for relative prices, the Engel curves lie on top of each other, and there is no horizontal translation (or scaling of nominal income in region/period $r, t$ ) that brings them closer together. To see this another way, note that the Hamilton method estimates $\ln \left(1+E_{t}\right)$ by $\frac{-\delta^{t}}{\beta^{f}}$; if preferences are homothetic, $\beta^{f}=0$ and this calculation involves dividing by zero.

The evidence that preferences are not homothetic is overwhelming. That food shares fall with income is Engel's law and has been confirmed by over a century of empirical studies of consumer demand (Engel, 1857, 1895; Working, 1943; Leser, 1963; Blundell, 1988). Thus the Hamilton method can be implemented, but the true cost of living differs across households; poor and rich households experience different changes in the cost of living because they consume different bundles, e.g. the poor spend a greater share of their budget on food.

Of course, the non-homotheticity of preferences also implies that the CPI, which is a

\footnotetext{
${ }^{5}$ With non-homothetic preferences, changes in the cost of living can be common across the income distribution in the specific instance of unchanging relative prices. But in general, relative prices do move. Moreover, if relative prices did not move, the problem of measuring cost of living differences across time and space would be simple: one need only find one well-measured price.
} 
single price index, estimates the cost of living at one point in the income distribution - an observation made long ago by Prais (1959) and Nicholson (1975). Therefore, the implication of preferences being non-homothetic is that the CPI and $P_{t}$ each estimate a cost of living index for a specific level of income but these two income levels need not be the same. We refer to the virtual household at the level of income at which the CPI estimates the cost of living as the CPI household. Correspondingly, we refer to the virtual household at the level of income at which $P_{t}$ estimates the cost of living as the Hamilton household.

Putting it all together, the Hamilton method's "bias", $E_{t}$, contains two elements:

1. CPI bias: The CPI differs from the true cost of living index of the CPI household due to substitution, new goods, quality changes, etc.

2. Non-homotheticity: The CPI household and Hamilton household have different levels of income, and so experience different changes in their true cost of living.

Previous analyses using the Hamilton method to assess CPI bias have conflated the two. ${ }^{6}$

\section{Whose cost of living?}

To disentangle genuine CPI bias from the effect of non-homotheticity, we first need to determine the locations of the CPI household and the Hamilton household in the income distribution.

For the CPI there is a well-established method for doing so due to Muellbauer (1976). The CPI household has expenditure shares that match the expenditure weights in the CPI. The expenditure weights in the CPI are the aggregate expenditure shares (that is the share of each good in total household spending). The aggregate expenditure share of good $k$ is in turn a weighted mean of household expenditure shares for good $k$, where each household is weighted by its share of total income:

\footnotetext{
${ }^{6}$ A different critique of the Hamilton method emphasized by Blow (2003) and Logan (2009) is that it is a residual-based method. Any time varying determinants of demand that are not accounted for will be attributed to CPI bias. See also Deaton and Dupriez (2011) and Ravallion (2015). Yet another critique of the method is that it fails to account for the introduction of new goods (see Bils and Klenow (2001a)).
} 


$$
W_{r, t}^{k}=\sum_{h} \frac{x_{h, r, t}}{\sum x_{h, r, t}} w_{h, r, t}^{k}
$$

Given this, and the Working-Leser functional form for household-level shares assumed above, we can write the aggregate share for food at time $t$, as:

$$
\begin{aligned}
W_{r, t}^{f} & =\sum_{h} \frac{x_{h, r, t}}{\sum x_{h, r, t}}\left[\alpha_{r, t}^{f}+\gamma^{f f} \ln \left(\frac{p_{r, t}^{f}}{p_{r, t}^{n}}\right)+\beta_{r, t}^{f} \ln \left(\frac{x_{h, r, t}}{P_{r, t}}\right)\right] \\
& =\alpha_{r, t}^{f}+\gamma^{f f} \ln \left(\frac{p_{r, t}^{f}}{p_{r, t}^{n}}\right)-\beta^{f} \ln P_{r, t}+\beta_{r, t}^{f} \sum_{h} \frac{x_{h, r, t} \ln \left(x_{h, r, t}\right)}{\sum x_{h, r, t}} .
\end{aligned}
$$

Thus the CPI household has income equal to $\sum_{h} \frac{x_{h, r, t} \ln \left(x_{h, r, t}\right)}{\sum x_{h, r, t}}$.

We compute where the income of the CPI household lies in the household income distribution for each year from 1974 to 1991 using the same PSID data as in Hamilton (001a). Results are illustrated in Figure 2, Panel A. Over this period, the aggregate shares used in the CPI correspond most closely to a household somewhere between the 68th and 77th percentile of the household income distribution. ${ }^{7}$ The CPI is a plutocratic index and so measures changes in the cost of living for a fairly affluent household. As noted above, as a measure of this household's true cost of living, the CPI may be biased because of substitution, new goods, quality changes and other biases discussed in the literature.

Turning to the Hamilton household, we begin with the general definition (in logarithms) of the true cost of living index (COLI) for a household $h$, in region $r$, at period $t$. We define reference utility for household $h, u_{h, 0}$, to be the utility of that household in the base region $(r=0)$ and base period $(t=0)$, where it faces the price vector $\mathbf{p}_{0}\left(=\mathbf{p}_{0,0}\right)$. In logarithms,

\footnotetext{
${ }^{7}$ Deaton (1998) similarly finds that the U.S. CPI is usually around the 75 th percentile of the household income distribution.
} 
Figure 2: Income Distribution Percentile of the CPI household

Panel A: Percentile for CPI household (1974-1991)



Panel B: Income distribution 1974

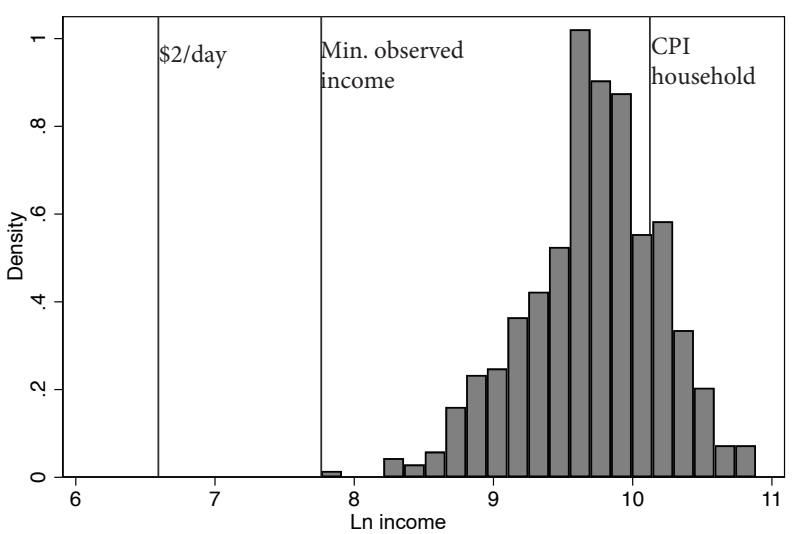

Note: Panel A displays the percentile location of the CPI household in the U.S. income distribution for different years. The CPI household is defined as a virtual household with income $\sum_{h} \frac{x_{h, r, t} \ln x_{h, r, t}}{\sum_{h} x_{h}, \text { Panel }}$ $\mathrm{B}$ shows the distribution of income in the PSID sample, the income of the CPI household, and the income of the Hamilton household under our two calibrations. 
the true COLI is then given by: ${ }^{8}$

$$
\ln C O L I_{h, r, t}=\ln C\left(u_{h, 0}, \mathbf{p}_{\mathbf{r}, \mathbf{t}}\right)-\ln C\left(u_{h, 0}, \mathbf{p}_{\mathbf{0}}\right),
$$

where $C\left(u_{h, 0}, \mathbf{p}_{\mathbf{r}, \mathbf{t}}\right)$ is the money cost of obtaining utility level $u_{h, 0}$ at prices $\mathbf{p}_{\mathbf{r}, \mathbf{t}}=\left[p_{r, t}^{f}, p_{r, t}^{n}\right]$. This COLI measures the resources necessary to maintain base-period utility at the new price vector $\mathbf{p}_{\mathbf{r}, \mathbf{t}}$ for this household, and the logarithm of the COLI measures the proportional change in required resources.

For AIDS preferences,

$$
\begin{aligned}
\ln C\left(u_{h, 0}, \mathbf{p}_{\mathbf{t}, \mathbf{r}}\right) & =\ln a\left(\mathbf{p}_{\mathbf{r}, \mathbf{t}}\right)+b\left(\mathbf{p}_{\mathbf{r}, \mathbf{t}}\right) f\left(u_{h, 0}\right), \\
\ln a\left(\mathbf{p}_{\mathbf{r}, \mathbf{t}}\right) & =\alpha_{0}+\sum_{k=f, n} \alpha_{k} \ln p_{r, t}^{k}+\sum_{k=f, n} \sum_{l=f, n} \gamma_{k, l} \ln p_{r, t}^{k} \ln p_{r, t}^{l}, \\
b\left(\mathbf{p}_{r, t}\right) & =\prod_{k=f, n}\left(p_{r, t}^{k}\right)^{\beta^{k}},
\end{aligned}
$$

where $\sum_{k=f, n} \alpha_{k}=1$ and $\sum_{k=f, n} \gamma_{k, l}=\sum_{l=f, n} \gamma_{k, l}=\sum_{k=f, n} \beta^{k}=0 . f()$ is a monotonic transformation. Note that it is standard to present a "canonical" form of AIDS preferences that omits this transformation but we retain it here to emphasize that what follows does not require a cardinalization of utility. Thus, given Hamilton's assumption of AIDS preferences, the true COLI is log-linear in a monotonic transformation utility, and not independent of utility (or income) as Hamilton implies.

The food share is:

$$
\begin{aligned}
& w_{h, r, t}^{f}=\alpha^{f}+\sum_{k=f, n} \gamma^{k} \ln p_{r, t}^{k}+\beta^{f} \ln \left(\frac{x_{h, r, t}}{a\left(\mathbf{p}_{\mathbf{r}, \mathbf{t}}\right)}\right) \\
& {\left[=\alpha^{f}+\sum_{k=f, n} \gamma^{k} \ln p_{r, t}^{k}+\beta^{f} \ln \left(\frac{x_{h, r, t}}{P_{r, t}}\right) \text { in Hamilton's notation }\right] . }
\end{aligned}
$$

Demands are of course independent of monotonic transformations of utility. Note also that $\ln a\left(\mathbf{p}_{\mathbf{r}, \mathbf{t}}\right)=\ln P_{r, t}$, which is the price index corresponding to the Hamilton household.

\footnotetext{
${ }^{8} u_{h, 0}$ is not the only possible choice of reference utility level, but is the natural choice for comparison with price indices, like the CPI, that use base period quantities as weights.
} 
In the base period and region, prices are set to 1 (and log prices are zero), so that, $\ln a\left(\mathbf{p}_{\mathbf{0}}\right)=\alpha_{0}$ and $b\left(\mathbf{p}_{\mathbf{0}}\right)=1 .{ }^{9}$ As cost in period/region 0 must be equal to observed income in period/region 0 , inverting gives transformed utility in the base period and region as a function of observed income $x_{h, 0}$ :

$$
f\left(u_{h}\right)=\ln x_{h, 0}-\alpha_{0}
$$

The cost of obtaining base period/region utility facing prices $\mathbf{p}_{\mathbf{r}, \mathbf{t}}$ is then

$$
\ln C\left(\mathbf{p}_{\mathbf{r}, \mathbf{t}}, u_{h, 0}\right)=\ln P_{r, t}+b\left(\mathbf{p}_{\mathbf{r}, \mathbf{t}}\right)\left(\ln x_{h, 0}-\alpha_{0}\right) .
$$

Note that Equation (13) is independent of the monotonic transformation $f()$. The linearity of log-costs in the logarithm of base period/region income is an ordinal property of the PIGLOG preferences underlying the AIDS demand system. Equation (13) shows that the Hamilton household has income level $\ln x_{h, 0}=\alpha_{0} . P_{r, t}$ is the true cost of living index only at this level of income. However, the value of $\alpha_{0}$ is not identified by the Hamilton method.

However, from the structure of the demand system, we know that $\alpha_{0}$ is such that the Hamilton household, in contrast to the CPI household, is a poor household. In the original AIDS paper, Deaton and Muellbauer (1980) show that the indifference curve associated with $\ln x_{h, 0}=\alpha_{0}$ in the base period/region (or equivalently with $f\left(u_{h, 0}\right)=0$ ) is the lowest obtainable indifference curve. It follows that $\alpha_{0}$ can be interpreted as "subsistence" log income at base period/region prices, the lowest viable income level. ${ }^{10}$ For this reason, researchers estimating the AIDS demand system often calibrate $\alpha_{0}$ to 0 (corresponding to a nominal income of 1 ) or to the lowest observed income in the base period/region sample (see for example Banks et al. (1997b)). As the latter is presumably a viable income, it provides a

\footnotetext{
${ }^{9}$ Note that this is a standard normalization. As we discuss price indices and not price levels, we normalize prices in one year, here chosen to be the base year. This choice of base year is arbitrary and does not drive the theory or the empirical results.

${ }^{10}$ The condition $0 \leq f(u) \leq 1$ is implicit in this representation of the PIGLOG preference structure. It insures that the cost function is concave and that real incomes (defined below) are always positive. Thus $f(u)=0$ is lowest possible indifference curve, and $\ln x_{h, 0}=\alpha_{0}$ is the income necessary to reach that indifference curve at base period and region prices. The monotonic transformation $f()$ reminds us that this property does not imply cardinal utility. See Deaton and Muellbauer (1980) and Banks et al. (1997b) for further discussion.
} 
logical upper bound to subsistence income. We return to the problem of deterimining exactly how poor the Hamilton household is below. For the moment, we note that $\ln P_{r, t}=\ln a\left(\mathbf{p}_{\mathbf{r}, \mathbf{t}}\right)$ is the $(\log )$ COLI associated with the poorest possible household. For any other household, including the quite affuent CPI household, the true COLI will differ from $\ln P_{r, t}$ due to nonhomotheticity (whenever relative prices change).

In order to decompose the Hamilton estimate into CPI bias and non-homotheticity effect, we start by solving Equation (13) for $\ln P_{r, t}$ and taking changes, which yields:

$$
\triangle \ln P_{r, t}=\triangle \ln C\left(\mathbf{p}_{\mathbf{r}, \mathbf{t}}, u_{h, 0}\right)-\Delta b\left(\mathbf{p}_{\mathbf{r}, \mathbf{t}}\right)\left(\ln x_{h, 0}-\alpha_{0}\right),
$$

Also recall from Section 2 that $E_{t}$ is defined as $P_{r, t}=P_{r, 0} C P I_{r, t}\left(1+E_{t}\right)$. Taking logs and changes (recalling that $C P I_{0,0}=1$ and $E_{0}=0$ ), and rearranging this expression yields:

$$
\Delta \ln P_{r, t}=\ln C P I_{r, t}+\ln \left(1+E_{t}\right) .
$$

Combining Equations (14) and (15) and rearranging then gives:

$$
\ln \left(1+E_{t}\right)=\left[\triangle \ln C\left(\mathbf{p}_{\mathbf{r}, \mathbf{t}}, u_{h, 0}\right)-\ln C P I_{r, t}\right]-\Delta b\left(\mathbf{p}_{\mathbf{r}, \mathbf{t}}\right)\left(\ln x_{h, 0}-\alpha_{0}\right) .
$$

Evaluating this expression at the income level of the CPI household $\left(x_{h, 0}=x^{C P I}\right)$ gives a natural decomposition of the Hamilton correction:

$$
\begin{aligned}
-\ln \left(1+E_{t}\right) & =\ln C P I_{r, t}-\Delta \ln P_{r, t}=\left[\ln C P I_{r, t}-\triangle \ln C\left(\mathbf{p}_{\mathbf{r}, \mathbf{t}}, u\left(x^{C P I}, \mathbf{p}_{r, t}\right)\right)\right] \\
& +\left[\Delta b\left(\mathbf{p}_{\mathbf{r}, \mathbf{t}}\right)\left(\ln x^{C P I}-\alpha_{0}\right)\right] .
\end{aligned}
$$

Hamilton's measure, $-\ln \left(1+E_{t}\right)$, captures the difference between the CPI $\left(\ln C P I_{r, t}\right)$ and the price index $\left(\Delta \ln P_{r, t}\right)$, and this measure can be further decomposed into actual CPI bias, which is given by the first term $\left[\ln C P I_{r, t}-\triangle \ln C\left(\mathbf{p}_{\mathbf{r}, \mathbf{t}}, u\left(x^{C P I}, \mathbf{p}_{r, t}\right)\right)\right]$, and the part due to non-homotheticity, which is given by the second term $\left[\Delta b\left(\mathbf{p}_{\mathbf{r}, \mathbf{t}}\right)\left(\ln x^{C P I}-\alpha_{0}\right)\right] .{ }^{11}$

\footnotetext{
${ }^{11}$ Note that Hamilton's assumption that $E$ varies only with time can only be approximately correct as the two components of $E$ vary with both time and region.
} 
This decomposition is illustrated in Figure 3. Each panel illustrates one of three possible cases. In each panel, the logarithm of base period nominal income is on the horizontal axis and the CPI, changes in $P_{t}$ and changes in the true cost of living (all in logarithms) are measured on the vertical axis. The change in the logarithm of the true cost of living from period/region 0 to period/region $t, r(\Delta \ln C)$ is given by the diagonal line. It varies with the household's income in the base period. The slope of this diagonal line is:

$$
\Delta b\left(\mathbf{p}_{\mathbf{r}, \mathbf{t}}\right)=\left(\frac{p_{r, t}^{f}}{p_{r, t}^{n}}\right)^{\beta^{f}}-\left(\frac{p_{0}^{f}}{p_{0}^{n}}\right)^{\beta^{f}}=\left(\frac{p_{r, 0}^{f}}{p_{r, 0}^{n}}\right)^{\beta^{f}}\left[\left(\frac{\left(1+\Pi_{r, t}^{f}\right)}{\left(1+\Pi_{r, t}^{n}\right)}\right)^{\beta^{f}}-1\right] .
$$

Food is a necessity, so $\beta_{f}<0$. Thus, if the relative price of food is lower in region/period $r, t$ than in region/period 0 , then $\Delta b\left(\mathbf{p}_{\mathbf{r}, \mathbf{t}}\right)>0$ and the diagonal line slopes up (as in panels (a) and (b)). If the relative price of food is higher in period $/ \mathrm{region} r, t$ than in period $/ \mathrm{region} 0$ then $\Delta b\left(\mathbf{p}_{\mathbf{r}, \mathbf{t}}\right)<\mathbf{0}$ and the diagonal line slopes down (as in panel (c)). Whatever the slope, the diagonal line for $\Delta \ln C$ always passes through the intersection of the vertical line at $\ln x_{h, 0}=\alpha_{0}$ and the horizontal line at $\triangle \ln P_{r, t}$. This is because the Hamilton method estimates the change in the cost of living at $\ln x_{h, 0}=\alpha_{0}$.

The decomposition above can be seen at the vertical line at $\ln x_{h, 0}=\ln x^{C P I}$. The difference between $\Delta \ln C$ and $\Delta \ln P$ is the part due to non-homotheticity $\left(\Delta b\left(\mathbf{p}_{\mathbf{r}, \mathbf{t}}\right)\left(\ln x^{C P I}-\right.\right.$ $\left.\alpha_{0}\right)$ ). In Panel (3a), this is positive, but less than $\Delta \ln P_{r, t}-\ln C P I_{r, t}$. The remaining gap between $\Delta \ln C$ and $\ln C P I$ is then CPI bias (the extent to which the CPI mismeasures the true cost of living increase for the CPI household), and this is also positive. In Panel (3b), the difference between $\Delta \ln C$ and $\Delta \ln P$ (due to non-homotheticity) is positive and exceeds $\Delta \ln P_{r, t}-\ln C P I_{r, t}$. This implies that the actual CPI bias must be negative, as indicated in the figure. In Panel (3c), the difference between $\Delta \ln C$ and $\Delta \ln P$ (due to non-homotheticity) is negative, so that actual CPI bias is greater than $\Delta \ln P_{r, t}-\ln C P I_{r, t}$.

Equation (16) can also be re-arranged to give an expression for the true COLI (at a given base period/region income) in terms of the CPI, the Hamilton Correction and a 
Figure 3: Three possible cases

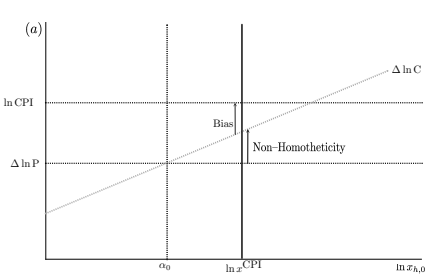

(a)

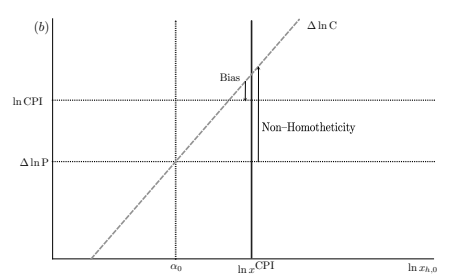

(b)

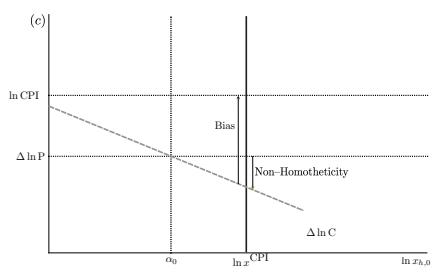

(c)

Note: The figure displays three possible cases. In each panel, the logarithm of base period nominal income is on the horizontal axis and the CPI, changes in $P_{t}$, and changes in the true cost of living (all in logarithms) are measured on the vertical axis. The change in the logarithm of the true cost of living from period/region $t, r$ to period/region $0(0,0)$ is given by the diagonal line. In panels (a) and (b) the relative price of food is lower in region/period $t, r$ than in region/period 0 and the diagonal line slopes up. In panel (a) the Hamilton method reports a positive CPI bias and the slope of the diagonal line is such that the Hamilton method overestimates the CPI bias. In panel (b) the Hamilton method also reports a positive bias and the slope is such that the bias is negative. In panel (c) the relative price of food is higher in region/period $t, r$ than in region/period 0 and the diagonal line slopes down. The Hamilton method underestimates the negative bias in CPI.

further correction for non-homotheticity:

$$
\Delta \ln C\left(\mathbf{p}_{\mathbf{r}, \mathbf{t}}, u_{h, 0}\right)=\ln C P I_{r, t}+\ln \left(1+E_{t}\right)+\Delta b\left(\mathbf{p}_{\mathbf{r}, \mathbf{t}}\right)\left(\ln x_{h, 0}-\alpha_{0}\right) .
$$

It follows that a household with $\log$ nominal income $\ln x_{h, 0}$ in the base period and region has "real" or deflated log income in period $t$ and region $r$ of:

$$
\ln x_{h, r, t}-\ln C P I_{r, t}-\ln \left(1+E_{t}\right)-\Delta b\left(\mathbf{p}_{\mathbf{r}, \mathbf{t}}\right)\left(\ln x_{h, 0}-\alpha_{0}\right) .
$$

(where $\ln x_{h, r, t}$ is $\log$ nominal income in period $t$ and region $r$.) We first deflate by the CPI, then apply Hamilton's correction and then apply a further correction for non-homotheticity.

To quantify true CPI bias we need to empirically implement the decomposition in Equation (17) into the part due to non-homotheticity and true CPI bias. This means calculating

$$
\Delta b\left(\mathbf{p}_{\mathbf{r}, \mathbf{t}}\right)\left(\ln x^{C P I}-\alpha_{0}\right)=\left(\frac{p_{r, 0}^{f}}{p_{r, 0}^{n}}\right)^{\beta^{f}}\left[\left(\frac{\left(1+\Pi_{r, t}^{f}\right)}{\left(1+\Pi_{r, t}^{n}\right)}\right)^{\beta^{f}}-1\right]\left(\ln x^{C P I}-\alpha_{0}\right),
$$


where $\beta^{f}$ is the slope of the Engel curve and easily estimated. The calculation of $\ln x^{C P I}$ was discussed above. Thus for a given region, $r$, expression (21) contains two unobservable quantities: $\alpha_{0}$ and the base period price ratio $\frac{p_{r, 0}^{f}}{p_{r, 0}^{n}}$. Note that in the base region $\frac{p_{0}^{f}}{p_{0}^{n}}=1$. But the choice of base period is an arbitrary normalization of prices. We can re-normalize prices so that, essentially, each region is the base region in turn. This requires an adjustment to $\alpha_{0}$ (because $\alpha_{0}$ is the logarithm of the cost of base utility when prices are 1 ), but this is straight forward. ${ }^{12}$

What remains is $\alpha_{0}$, the subsistence level of income. This parameter is in principle identified by demand responses if price levels were perfectly observed, but is not identified given data like that used by Hamilton. In an earlier working paper version of this note, we show this, and consider alternative methods of estimating and bounding $\alpha_{0}$ (Almås et al., 2018). None of the methods we consider give satisfactory precision in Hamilton's data.

In our empirical application below we instead take the approach of calibrating the subsistence income in the base region/year. We consider two alternative calibrations. First, following the literature on empirical estimation of the AIDS demand system, we calibrate $\alpha_{0}$ to the lowest observed income in the base period/region sample. As noted above the lowest reported income is a natural upper bound to subsistence income. Moreover, as a smaller value of $\alpha_{0}$ implies a larger nonhomotheticity adjustment, taking an upper bound for subsistence income results in a conservative correction to the Hamilton procedure. Our second calibration value for $\alpha_{0}$ is $\$ 2$ a day (in the base region/year). Much recent discussion of extreme poverty in the U.S. has focused on this number (Edin and Shaefer, 2015). This is below the minimum base region/period income observed in the Hamilton data, and the preferred point estimate for $\alpha_{0}$ in those data reported by Almås et al. (2018) lies between these two values. Thus these two calibration values cover the plausible range for this parameter, and hence for the income-location of the Hamilton Household. ${ }^{13}$ Our two calibration values, as well as the income-location of the CPI are shown in Panel B of Figure (2) against the distribution of income in the base year (1974).

\footnotetext{
${ }^{12}$ Almås et al. (2018) describe the calculations.

${ }^{13}$ Converting to a monthly value and taking logs, $\$ 2$ a day corresponds to 6.59 . The lowest base region/year log income in the data is 7.83 and the Almås et al. (2018) estimate is 7.57.
} 
Our key insight is that any use of Engel curve shifts to draw inferences about the cost of living or real incomes must account for nonhomotheticity in consumer preferences. Two recent papers use this insight in closely related ways. First, in response to a very early version of this paper (Beatty and Crossley, 2012), Nakamura et al. (2016) check the robustness of Hamilton method inflation estimates for China by calculating exact price indices for different parts of the observed income distribution. They employ Divisia indices from Feenstra and Reinsdorf (2000) which are exact for the Almost Ideal Demand System (for one particular path of prices). These indices require only data on initial and final period expenditure shares and prices for the relevant groups. Inflation rates so calculated differ across income groups in China, but the differences are small. This procedure is an elegant way of assessing the slope of the change in cost of living (the line labeled $\Delta \ln C$ in Figure 3), but it is unable to assess its location. Nevertheless, if one assumes that the subsistence income level represented by the Hamilton household is within the observed income distribution, then a shallow slope suggests that the required nonhomotheticity correction is modest. In China, and in less developed countries, this may be a reasonable assumption. Second, in a recent working paper, Atkin et al. (2018) study the regional impact of trade reforms in India using Engel curve shifts. They employ the same insight regarding the importance of accounting for nonhomotheticity, along with an assumption of quasi-separable preferences, and develop an approach that combines information from multiple Engel curves.

As noted above, our work and these related papers fit into a growing literature that explicitly incorporates non-homothetic preferences - across several fields. Fieler (2011) incorporates non-homothetic preferences into a Ricardian trade model and suggests that the income elasticity of trade is such that a positive technology shock in China makes poor and rich countries better off and middle-income countries worse off. Bems and Di Giovanni (2017) study the expenditure shifting that happened in Latvia in relation to the $2008 / 2009$ financial crisis. Their results indicate that the switching is driven by income, not changes in relative prices. Boppart (2014) develops a growth model with non-homothetic preferences and applies it to study and decompose structural change in the U.S. after World War II into income and substitution effects. His results attribute a substantial share of structural change 


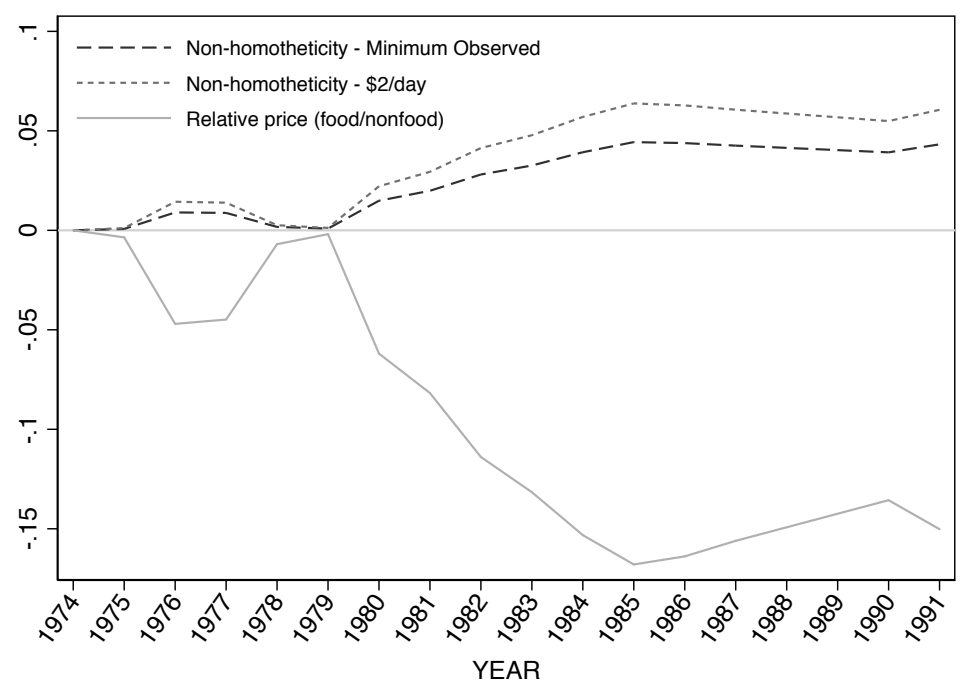

Figure 4: Relative Prices \& Non-homotheticity

Note: The figure charts the evolution of the relative price of food to non-food goods, over the period studies by Hamilton (solid line). The difference in the change in log cost-of-living for the CPI household and the change in the log cost of living of the Hamilton Household is given by the dashed lines (one for each of our calibrations).

to income changes. Handbury (2013) studies spatial price differences in the U.S. by using Nielsen household-level purchase data of food products and shows that using homothetic cost-of-living indexes understates the relative price level in poor locations for rich households. Moretti (2013) studies the wage gap between high skilled and low skilled in the U.S. and reports that when deflating nominal wages using a location-specific CPI, the difference between the wage of college graduates and high school graduates is lower in deflated terms than in nominal terms and has grown less.

We now turn to an empirical application of the decomposition developed above.

\section{Application}

We use PSID data as Hamilton (001a) to estimate the change in cost of living for the CPI household, and hence CPI bias.

The solid line in the lower panel of Figure 4 charts the evolution of the relative price 
of food (to non-food goods) over the period Hamilton studies. In this time period, food prices fell relative to non-food prices, so that rich households experienced larger cost-ofliving increases than poor households. Together with the fact that the log income level of the Hamilton household is far below the log income level of the CPI household, this implies that the true change in cost-of-living was smaller for the Hamilton household than for the CPI household. The excess in the change in cost-of-living for the CPI household over the change in the cost of living of the Hamilton household is given by the dashed lines in the upper panel of Figure 4 (one for each of our calibrations); both lines indicate a positive excess. This difference in true changes in cost-of-living implies that the difference between the change for the Hamilton household and the CPI overstates the bias in the CPI. That is, the CPI household experienced a larger cost-of-living increase than that estimated by the Hamilton method, because the Hamilton household is poorer than the CPI household. Hence, the scenario that turns out to be relevant for these data and this period is captured by Panel (a) in Figure 3.

Our two estimates of CPI bias are both presented, and compared to that of the Hamilton method, in Table 1. Column 2 displays our replication of Hamilton's original estimates ${ }^{14}$, column 3 displays the results for our estimates based on the $\$ 2$ /day income level, and column 4 displays the results based on the minimum observed income level in the data. Both our estimates of cumulative CPI bias are smaller than Hamilton's. By the end of the period our estimates reveal a cumulative CPI bias in a range of 4 to 6 percentage points lower than Hamilton's. Nevertheless, after correcting for non-homotheticity, we continue to find a significant upward bias in the CPI in this period, with cumulative bias over the 15 years of 22 or 23 percentage points.

\section{Conclusion}

The Hamilton method as proposed and often used confounds genuine CPI bias with differences in consumption baskets across the income distribution. We have argued that, as the

\footnotetext{
${ }^{14}$ The appropriate comparison is to his 25 -SMSA sample estimates. Our numbers differ very slightly, due to subsequent revisions to the PSID
} 
Table 1: Comparing CPI Bias computed according to Hamilton and Corrected Methods

\begin{tabular}{cccc}
\hline \hline Year & Hamilton & $\$ 2 /$ day & Min Obs \\
\hline 1974 & - & - & - \\
1975 & 0.050 & 0.049 & 0.050 \\
1976 & 0.122 & 0.108 & 0.113 \\
1977 & 0.106 & 0.092 & 0.097 \\
1978 & 0.133 & 0.130 & 0.131 \\
1979 & 0.167 & 0.166 & 0.166 \\
1980 & 0.212 & 0.190 & 0.197 \\
1981 & 0.199 & 0.169 & 0.179 \\
1982 & 0.220 & 0.178 & 0.191 \\
1983 & 0.240 & 0.192 & 0.207 \\
1984 & 0.280 & 0.223 & 0.241 \\
1985 & 0.257 & 0.194 & 0.213 \\
1986 & 0.257 & 0.194 & 0.213 \\
1987 & 0.266 & 0.206 & 0.224 \\
1990 & 0.280 & 0.225 & 0.241 \\
1991 & 0.277 & 0.216 & 0.234 \\
\hline
\end{tabular}

Note: The table shows the cumulative bias for the Hamilton and our two choices for $\alpha_{0}$. The cumulative bias for the Hamilton method is given by $E_{t}=\exp \left[-\frac{\delta^{t}}{\beta^{f}}\right]-1$ and the cumulative bias for the calibration methods are given by $B_{t}=\exp \left[-\frac{\delta^{t}}{\beta^{f}}+\Delta b\left(\mathbf{p}_{\mathbf{r}, \mathbf{t}}\right)\left(\ln x_{h, 0}^{C P I}-\alpha_{0}\right)\right]-1$ for different choices of $\alpha_{0}$.

Hamilton method requires non-homotheticity to be implemented, non-homotheticity must be accounted for in interpreting the movement in Engel curves over time or space. We have demonstrated how to do this by developing a method that disentangles genuine price index bias from differences in consumption baskets across the income distribution. In this way, the Hamilton method can be made internally consistent.

For the data and period that Hamilton studies, our method leads to smaller, but still important, estimates of cumulative upward bias in the CPI. The CPI is often used as a deflator when measuring changes in real income over time. Our results therefore have implications for the ongoing debate about the stagnation of incomes in the United States (Piketty and Saez, 2007). An upward bias in the CPI leads to an underestimation of income growth. $^{15}$ And indeed, Hamilton's results and Hamilton's method have sometimes been

\footnotetext{
${ }^{15}$ Strictly speaking, and as we have demonstrated, the CPI only reflects cost of living changes for a relatively affluent household and as such we may want to use income specific deflators when discussing real income growth. Our approach could in principle also help with such a detailed analysis, but as we have chosen to here focus on CPI and not real income changes, we consider such an analysis to be beyond the scope of this paper.
} 
used in support for the claim that the official numbers on real income growth are too low. Our analysis also gives support to this: the CPI is upwards biased, i.e., price growth is lower than the CPI indicates, and hence real income growth is larger than that suggested by the $\mathrm{CPI}$ as a deflator. However, our results also indicate that the original results presented by Hamilton suggest too large a bias, and thus, real income growth is not as high as indicated by the original Hamilton method. 


\section{References}

Almås, I. (2012). International Income Inequality: Measuring PPP Bias by Estimating Engel Curves for Food. American Economic Review, 102(2):1093-1117.

Almås, I., Beatty, T. K., and F., C. T. (2018). Lost in translation: What do Engel curves tell us about the cost of living? Working paper 18-04, Working Paper, Institute for Fiscal Studies.

Almås, I. and Johnsen, Å. A. (2018). The cost of a growth miracle-reassessing price and poverty trends in China. Review of Economic Dynamics, 30:239-264.

Atkin, D., Faber, B., Fally, T., and Gonzalez-Navarro, M. (2018). A New Engel on the Gains from Trade. Working paper.

Banks, J., Blundell, R., and Lewbel, A. (1997a). Quadratic Engel Curves and Consumer Demand. The Review of Economics and Statistics, 79(4):527-539.

Banks, J., Blundell, R., and Lewbel, A. (1997b). Quadratic Engel curves and consumer demand. Review of Economics and statistics, 79(4):527-539.

Barrett, G. F. and Brzozowski, M. (2010). Using Engel Curves to Estimate the Bias in the Australian CPI. Economic Record, 86(272):1-14.

Beatty, T. K. and Larsen, E. R. (2005). Using Engel Curves to Estimate Bias in the Canadian CPI as a Cost of Living Index. Canadian Journal of Economics, 38(2):482-499.

Beatty, T. K. M. and Crossley, T. F. (2012). Lost in Translation: What Do Engel Curves Tell Us About the Cost of Living. Working paper.

Bems, R. and Di Giovanni, J. (2017). Income-induced Expenditure Switching. American Economic Review, 106(12):3898-3931.

Bils, M. and Klenow, P. J. (2001a). The acceleration of variety growth. American Economic Review, 91(2):274-280. 
Bils, M. and Klenow, P. J. (2001b). Quantifying Quality Growth. American Economic Review, 91(4):1006-1030.

Blow, L. (2003). Explaining Trends in Household Spending. Working paper 03/06, Institute for Fiscal Studies.

Blundell, R. (1988). Consumer behaviour: theory and empirical evidence-A survey. The Economic Journal, 98(389):16-65.

Boppart, T. (2014). Structural Change and the Kaldor Facts in a Growth Model with Relative Price Effects and Non-Gorman Preferences. Econometrica, 82(6).

Boskin, M. J., Dulberger, E. R., Gordon, R. J., Griliches, Z., and Jorgenson, D. W. (1998). Consumer Prices, the Consumer Price Index, and the Cost of Living. Journal of Economic Perspectives, 12(1):3-26.

Boskin, M. J. and Jorgenson, D. W. (1997). Implications of Overstating Inflation for Indexing Government Programs and Understanding Economic Progress. American Economic Review, 87(2):89-93.

Broda, C. and Weinstein, D. E. (2010). Product Creation and Destruction: Evidence and Price Implications. American Economic Review, 100(3):691-723.

Brzozowski, M. (2006). Does One Size Fit All? The CPI and Canadian Seniors. Canadian Public Policy, 32(4):387-411.

Chattopadhyay, S. (2010). District Level Poverty Estimation: A Spatial Approach. Economics Bulletin, 30(4):2962-2977.

Chung, C., Gibson, J., and Kim, B. (2010). CPI Mismeasurements and Their Impacts on Economic Management in Korea. Asian Economic Papers, 9(1):1-15.

Clerc, M. et al. (2011). Does the CPI Reflect Changes in the Cost of Living in France? What the Analysis of Engel Curves Tells Us. Economie \& Statistique. 
Coondoo, D., Majumder, A., and Chattopadhyay, S. (2011). Estimating Spatial Consumer Price Indices Through Engel Curve Analysis. Review of Income and Wealth, 57(1):138155.

Costa, D. (2001). Estimating Real Income in the United States from 1888 to 1994: Correcting CPI Bias Using Engel Curves. Journal of Political Economy, 109(6):1288-1310.

Dabalen, A., Gaddis, I., and Nguyen, N. N. (2016). CPI Bias and its Implications for Poverty Reduction in Africa. World Bank Policy Research Working Paper, (7907).

de Carvalho Filho, I. and Chamon, M. (2012). The Myth of Post-reform Income Stagnation: Evidence From Brazil and Mexico. Journal of Development Economics, 97(2):368-386.

Deaton, A. (1998). Getting Prices Right: What Should be Done? Journal of Economic Perspectives, 12(1):37-46.

Deaton, A. and Dupriez, O. (2011). Purchasing Power Parity Exchange Rates for the Global Poor. American Economic Journal: Applied Economics, 3(2):137-66.

Deaton, A. and Heston, A. (2010a). Understanding PPPs and PPP-Based National Accounts. American Economic Journal: Macroeconomics, 2(4):1-35.

Deaton, A. and Muellbauer, J. (1980). An Almost Ideal Demand System. American Economic Review, 70(3):312-326.

Diewert, W. E. (1987). The New Palgrave: A Dictionary of Economics, volume 2, chapter Index Numbers, pages 767-780. The Macmillian Press, London.

Diewert, W. E. (1993). Essays in Index Number Theory, chapter The early history of price index research, pages 33-65. North Holland.

Diewert, W. E. (1995). Axiomatic and Economic Approaches to Elementary Price Indexes. Working Paper 5104, National Bureau of Economic Research.

Edin, K. J. and Shaefer, H. L. (2015). \$2.00 a day: Living on almost nothing in America. Houghton Mifflin Harcourt. 
Engel, E. (1857). Die productions-und consumtionsverhältnisse des königreichs sachsen. Zeitschrift des Statistischen Bureaus des Königlich Sächsischen Ministeriums des Innern, $8: 1-54$.

Engel, E. (1895). Die Lebenskosten belgischer Arbeiter-Familien früher und jetzt. C. Heinrich.

Feenstra, R. C. and Reinsdorf, M. B. (2000). An Exact Price Index for the Almost Ideal Demand System. Economics Letters, 66(2):159-162.

Fieler, A. C. (2011). Nonhomotheticity and bilateral trade: Evidence and a quantitative explanation. Econometrica, 79(4):1069-1101.

Gibson, J. and Scobie, G. (2010). Using Engel Curves to Estimate CPI Bias in A Small, Open, Inflation-targeting Economy. Applied Financial Economics, 20(17):1327-1335.

Gibson, J., Stillman, S., and Le, T. (2008). CPI Bias and Real Living Standards in Russia During the Transition. Journal of Development Economics, 87(1):140-160.

Greenlees, J. S. and McClelland, R. (2011). Does Quality Adjustment Matter for Technologically Stable Products? An Application to the CPI for Food. American Economic Review, 101(3):200-205.

Hamilton, B. W. (1998). The True Cost of Living: 1974-1991. Working paper 395, John Hopkins University, Department of Economics.

Hamilton, B. W. (2001a). Using Engel's Law to Estimate CPI Bias. American Economic Review, 91(3):619-630.

Hamilton, B. W. (2001b). Black-White Differences in Inflation: 1974-1991. Journal of Urban Economics, 50(1):77-96.

Handbury, J. (2013). Are Poor Cities Cheap for Everyone? Non-homotheticity and the Cost of Living Across U.S. Cities. Working paper 71, University of Pennsylvania - The Wharton School. 
Hausman, J. (2003). Sources of Bias and Solutions to Bias in the Consumer Price Index. Journal of Economic Perspectives, 17(1):23-44.

Hausman, J. and Leibtag, E. (2009). Price Index Concept and Measurement, chapter CPI Bias from Supercenters: Does the BLS Know that Wal-Mart Exists?, pages 203-231. University of Chicago Press.

Hill, R. J. (2004). Constructing Price Indexes across Space and Time: The Case of the European Union. American Economic Review, 94(5):1379-1410.

Larsen, E. R. (2007). Does the CPI Mirror the Cost of Living? Engel's Law Suggests Not in Norway. The Scandinavian Journal of Economics, 109(1):177-195.

Lebow, D. E. and Rudd, J. B. (2003). Measurement Error in the Consumer Price Index: Where Do We Stand? Journal of Economic Literature, 41(1):159-201.

Leser, C. E. V. (1963). Forms of Engel functions. Econometrica: Journal of the Econometric Society, pages 694-703.

Logan, T. D. (2009). Are Engel Curve Estimates of CPI Bias Biased? Historical Methods: A Journal of Quantitative and Interdisciplinary History, 42(3):97-110.

Meyer, B. D. and Sullivan, J. X. (2009). Five Decades of Consumption and Income Poverty. Working Paper 14827, National Bureau of Economic Research.

Meyer, B. D. and Sullivan, J. X. (2011). Viewpoint: Further Results on Measuring the Well-being of the Poor Using Income and Consumption. Canadian Journal of Economics, $44(1): 52-87$.

Meyer, B. D. and Sullivan, J. X. (2012). Identifying the Disadvantaged: Official Poverty, Consumption Poverty, and the New Supplemental Poverty Measure. Journal of Economic Perspectives, 26(3):111-136.

Moretti, E. (2013). Real Wage Inequality. American Economic Journal: Applied Economics, $5(1): 65-103$. 
Muellbauer, J. (1976). Community Preferences and the Representative Consumer. Econometrica, 44(5):979-999.

Nakamura, E., Steinsson, J., and Liu, M. (2016). Are Chinese Growth and Inflation Too Smooth? Evidence from Engel Curves. American Economic Journal: Macroeconomics, 8(3):113-144.

Nakamura, L. I. (1995). Is U.S. Economic Performance Really That Bad? Working Papers 95-21, Federal Reserve Bank of Philadelphia.

Neary, P. (2004). Rationalizing the Penn World Table: True Multilateral Indices for International Comparisons of Real Income. American Economic Review, 94(5):1411-1428.

Nicholson, J. L. (1975). Whose Cost of Living? Journal of the Royal Statistical Society. Series A (General), 138(4):540-542.

Nordhaus, W. D. (1998). Quality Change in Price Indexes. Journal of Economic Perspectives, 12(1):59-68.

Olivia, S. and Gibson, J. (2012). Using Engel Curves to Measure CPI Bias for Indonesia. Working Paper 13, Monash Business School, Department of Econometrics and Business Statistics.

Piketty, T. and Saez, E. (2007). Income and wage inequality in the United States, 1923-2002. Top Incomes Over the Twentieth Century: A Contrast Between Continental European and English-Speaking Countries, 141.

Pollak, R. A. (1998). The Consumer Price Index: A Research Agenda and Three Proposals. Journal of Economic Perspectives, 12(1):69-78.

Prais, S. J. (1959). Whose Cost of Living? The Review of Economic Studies, 26(2):126-134.

Ravallion, M. (2015). Toward Better Global Poverty Measures. Working Paper 417, Center for Global Development. 
Reinsdorf, M. B. (1993). Price Measurements and Their Uses, chapter The Effect of Outlet Price Differentials on the U.S. Consumer Price Index, pages 227-258. National Bureau of Economic Research.

Reinsdorf, M. B. (1998). Formula Bias and Within-stratum Substitution Bias in the U.S. CPI. The Review of Economics and Statistics, 80(2):175-187.

Sacerdote, B. I. (2017). Fifty Years Of Growth In American Consumption, Income, and Wages. Working Paper 23292, National Bureau of Economic Research.

Schultze, C. L. (2003). The Consumer Price Index: Conceptual Issues and Practical Suggestions. Journal of Economic Perspectives, 17(1):3-22.

Triplett, J. E. (2001). Should the Cost-of-living Index Provide the Conceptual Framework for A Consumer Price Index? The Economic Journal, pages 311-334.

Working, H. (1943). Statistical laws of family expenditure. Journal of the American Statistical Association, 38(221):43-56.

Xu, Y. and Zeng, W. (2009). Estimation of CPI Bias with Chinese City Statistical Data. Statistical Research, 4:2. 